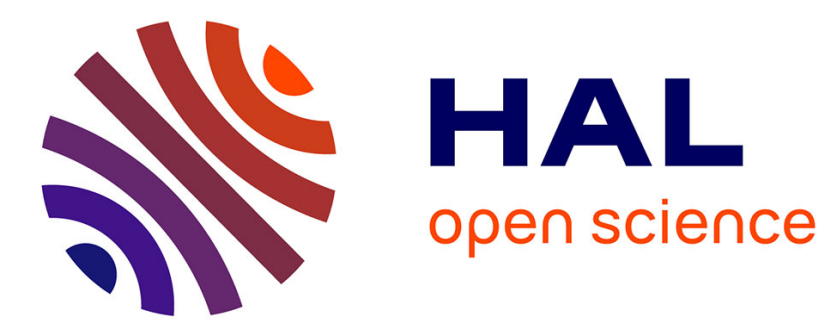

\title{
Price relationships in the EU emissions trading system Julien Chevallier
}

\section{To cite this version:}

Julien Chevallier. Price relationships in the EU emissions trading system. 2010. halshs-00458728

\section{HAL Id: halshs-00458728 \\ https://shs.hal.science/halshs-00458728}

Preprint submitted on 22 Feb 2010

HAL is a multi-disciplinary open access archive for the deposit and dissemination of scientific research documents, whether they are published or not. The documents may come from teaching and research institutions in France or abroad, or from public or private research centers.
L'archive ouverte pluridisciplinaire HAL, est destinée au dépôt et à la diffusion de documents scientifiques de niveau recherche, publiés ou non, émanant des établissements d'enseignement et de recherche français ou étrangers, des laboratoires publics ou privés. 


\title{
Price relationships in the EU emissions trading system
}

\author{
Julien Chevallier ${ }^{1}$ \\ Université Paris Dauphine
}

\begin{abstract}
The Emissions Trading Scheme (ETS) constrains industrial polluters to buy/sell $\mathrm{CO}_{2}$ allowances depending on a regional depolluting objective of -8\% of $\mathrm{CO}_{2}$ emissions by 2012 compared to 1990 levels. Companies may also buy carbon offsets from developing countries, funding emissions cuts there instead, under a Kyoto Protocol Clean Development Mechanism (CDM). This article critically analyzes the price relationships in the EU emissions trading system. The United Nations Framework Convention on Climate Change (UNFCCC) delivers credits that may be used by European companies for their compliance needs. Certified Emissions Reductions (CERs) from CDM projects are credits flowing into the global compliance market generated through emission reductions. EUAs (EU Allowances) are the tradable unit under the EU ETS. Besides, the EU Linking Directive allows the import for compliance into the EU ETS up to $13.4 \%$ of CERs on average. This article details the idiosyncratic risks affecting each emissions market, be it in terms of regulatory uncertainty, economic activity, industrial structure, or the impact of other energy markets. Besides, based on a careful analysis of the EUA and CER price paths, we assess common risk factors by focusing more particularly on the role played by the CER import limit within the ETS.
\end{abstract}

Keywords: Kyoto Protocol; Clean Development Mechanism; EU Emissions Trading Scheme; Greenhouse Gases Reductions; Emissions Markets; CDM; EU ETS

\footnotetext{
${ }^{1}$ Julien Chevallier is Member of the Centre de Géopolitique de l'Energie et des Matières Premières (CGEMP) and the Laboratoire d'Economie de Dauphine (LEDa). He is also Visiting Researcher with EconomiX-CNRS and the Grantham Institute for Climate Change at Imperial College London. Address for correspondence: Place du Maréchal de Lattre de Tassigny, 75775 Paris Cedex 16, France. Email : julien.chevallier@dauphine.fr
} 


\section{INTRODUCTION}

The Emissions Trading Scheme (ETS) is the EU's flagship climate policy, forcing industrial polluters to buy/sell $\mathrm{CO}_{2}$ allowances above a pre-specified emissions cap. Companies may cut the costs imposed on the industry by buying relatively cheaper carbon offsets from developing countries, funding emissions cuts there instead, under the Kyoto Protocol's Clean Development Mechanism (CDM). As the latest Intergovernmental Panel on Climate Change (IPCC, 2007) report pointed out the huge potential for the growth of $\mathrm{CO}_{2}$ emissions and associated pollutants in non-Annex B countries of the Kyoto Protocol, this article critically analyses to what extent the link between the EU ETS and the CDM will contribute to cut $\mathrm{CO}_{2}$ emissions by 2020 .

According to the article 12 of the Kyoto Protocol, projects under the Clean Development Mechanism consist in achieving greenhouse gases emissions reduction in nonAnnex B countries. After validation, the United Nations Framework Convention on Climate Change (UNFCCC) delivers credits that may be used by Annex B countries for use towards their compliance position. Certified Emissions Reductions (CERs) from CDM projects are credits flowing into the global compliance market generated through emission reductions. EUAs (EU Allowances) are the tradable units under the EU ETS. Albeit being determined on distinct emissions markets, CERs and EUAs may be exchanged based on their representative trading unit. One CER is equal to one ton of $\mathrm{CO}_{2}$-equivalent emissions reduction, while one EUA is equal to one ton of $\mathrm{CO}_{2}$ emitted in the atmosphere.

Besides, the EU Linking Directive ${ }^{2}$ allows the import of CERs into the EU ETS up to $13.4 \%$ of their compliance needs on average. The import limit is equal to 1.7 billion tonnes of offsets being allowed into the EU ETS from 2008-2020, that is, an absolute maximum of

\footnotetext{
${ }^{2}$ See http://ec.europa.eu/environment/climat/emission/linking_en.htm
} 
$50 \%$ of the depolluting effort fixed by the scheme will be achievable through the CDM. Overall, our results shed light on the importance of the link between the EU ETS and the $\mathrm{CDM}$ to foster investments in infrastructure technology in developing countries, thereby facilitating the transition to a low-carbon future.

The remainder of the article is organized as follows. First, we detail the idiosyncratic risks affecting each emissions market, be it in terms of regulatory uncertainty or economic factors. Second, based on a careful analysis of the EUA and CER price paths, we assess common risk factors by focusing more particularly on the role played by the CER import limit within the EU ETS.

\section{IDIOSYNCRATIC RISKS}

In this section, we comment first on the price developments of EUAs and CERs. Second, we examine the idiosyncratic risk factors for each emissions market.

\section{Price development}

Primary CERs (pCERs) have a delivery risk, while secondary CERs (sCERs) are already generated and issued by the CDM Executive Board, and are hence risk-free. The risks attached to primary CERs are linked to the United Nations" "International Transaction Log" (ITL) connection, the import limit, and the performance for operating projects, to which we may add a high volume of registered projects, as well as registration and methodological risks for proposed projects. The risks attached to secondary CERs are the ITL connection, the import limit, and eligibility criteria to be met for transfer of a CER from one EU registry to 
another. In the exchange contract (sCER), the seller agrees to pay EUAs or cash in case of non-delivery.

\section{Figure 1: EUA, CER, and EUA-CER Spread Prices}

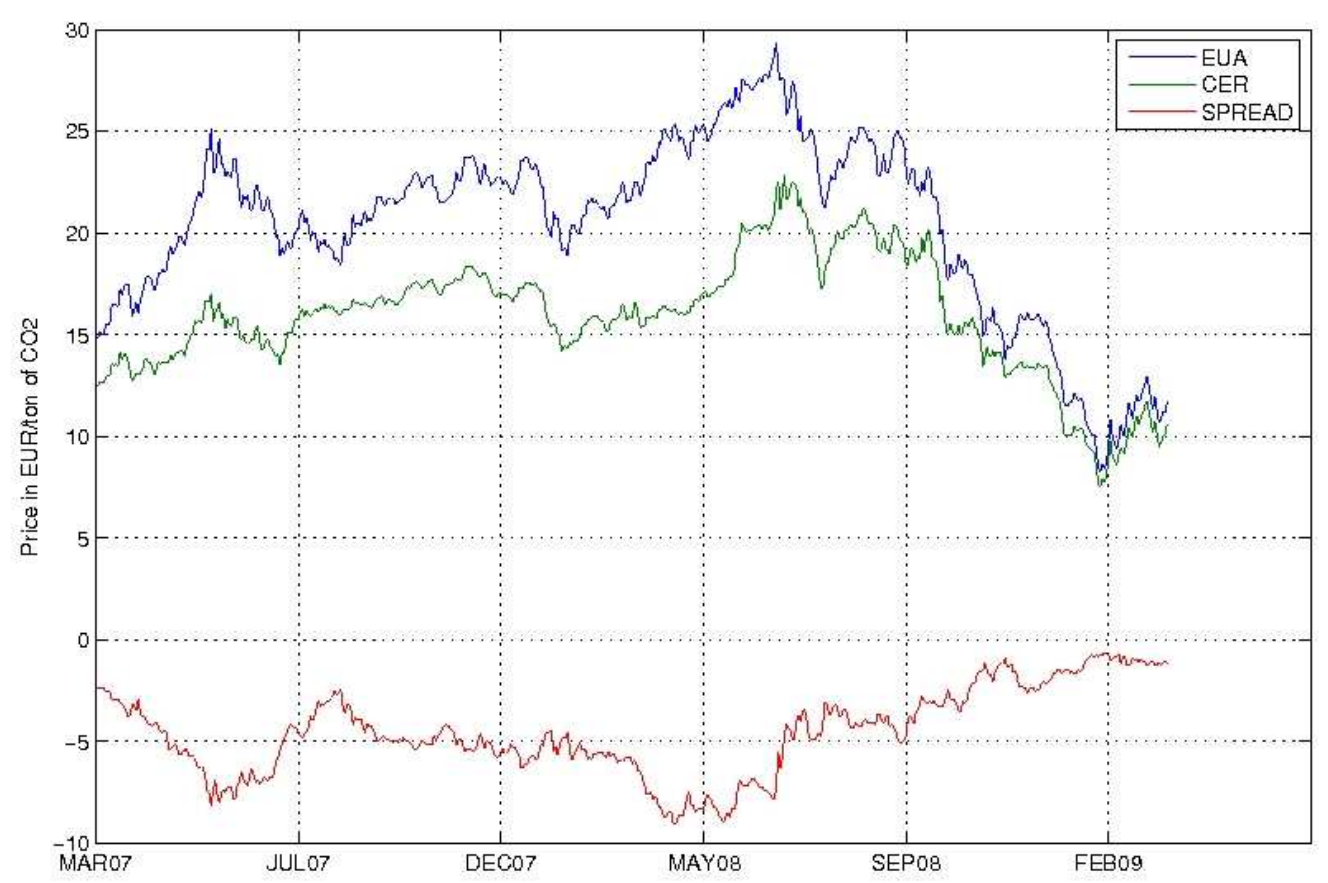

Source: European Climate Exchange

The CER and EUA price series in Figure 1 shows that we are in presence of correlated emissions markets. The CER-EUA spread presented at the bottom of Figure 1 represents arbitrage opportunities for traders who are able to identify pricing anomalies between the quoted spread price and the two emissions markets. ${ }^{3}$ The EUA spread over the secondary CER widened to nearly $€ 10$ in Figure 1 , and was even higher for most primary CER contracts. We may also observe that the CER-EUA spread varies in the range of $€-1.5$ on 20 November 2008, and has been as high as €-9 during 2008. A broad spread means that

\footnotetext{
${ }^{3}$ Note that CERs traded on exchanges are precisely guaranteed secondary CERs (sCERs), but for simplicity we use the common denomination term of CERs throughout the article.
} 
there is a high risk premium in the purchase of CERs compared to EUAs. At the same time, it means that there are large arbitrage opportunities to use CERs for compliance within the EU ETS, since they are a lot cheaper than EUAs. A narrow CER-EUA spread could also mean lower demand for CERs, which may discourage project developers from investing in cleaner energy facilities.

This analysis brings us to investigate the respective risk factors of CERs and EUAs.

2. Risk factors specific to CDM credits

CDM projects add value to an investment through CER revenues. CDM projects are registered by the CDM Executive Board, and displayed in the CDM pipeline ${ }^{4}$ along the several steps from registration to validation. One particularly striking source of uncertainty concerning the validation of CDM projects lies in the so-called "additionality" of GHG emissions reductions claimed; that is, project developers need to demonstrate the GHG emissions reductions claimed would not have been achieved in the absence of the project. According to the World Bank (2008), the CDM projects' distribution is skewed toward a small group of developing host countries: five countries (China, India, Brazil, Mexico, South Korea) concentrate around $80 \%$ of the total project pipeline. These countries have been able to streamline their CDM project identification and approval procedures at an early stage. Moreover, these countries offered several large-scale project opportunities which are generally attractive as they enable investors to spread project transaction costs across a larger number of CERs. Most projects are in the category of renewable energy and biomass energy production: $26 \%$ of $\mathrm{CDM}$ projects involve hydropower technology, $15 \%$ biomass-based energy production, and $14 \%$ wind energy. China concentrates $66 \%$ of hydropower projects,

\footnotetext{
${ }^{4}$ See http: $\backslash \backslash w w w . c d m p i p e l i n e . o r g$
} 
and India $68 \%$ of biomass energy projects. Together, those countries host $90 \%$ of wind energy projects. With such a geographic concentration, CER prices are sensitive to a large inflow of validated credits (e.g. from China or India). ${ }^{5}$

The risk factors specific to primary and secondary CERs are as follows. On the primary market, there needs to be (i) an increased predictability of issuance and frequency of transfer CERs by the CDM EB, (ii) an ITL operational and linked to the EU registry system, and (iii) the development of a robust options market. On the secondary market, we need to accound for (i) the acceptance into EU registries of CDM credits, (ii) the development of new emissions trading schemes which increase sCER demand and thus push CER prices to converge with other carbon prices under compliance schemes, and (iii) limitations on the use of CERs compliance under the EU ETS. Finally, both pCERs and sCERs are affected by the uncertainties concerning the post-2012 climate regime.

3. Risk factors specific the European carbon market

There are three main sources of risk in the EU ETS. First, the free permits distributed to existing firms on a "first-come, first-served" basis represent a market value of $€ 40$ billion that was created at the same time as $\mathrm{CO}_{2}$ emissions were capped. This allocation methodology is also known as grandfathering. Since 1 January 2005, carbon allowances form another asset in commodities against which industrials and brokers need to hedge. As the volume of transaction on the EU ETS has increased steadily from 262 million tons in 2005 to 1,443 million tons in 2007 , this trading activity reflects market participants' progressive learning of this new financial market.

\footnotetext{
5 To conserve space, we do not comment here on the concept of "programmatic" CDM, which has been developed for small-scale projects.
} 
Second, during Phase I of the EU ETS (2005-2007), EUAs experienced a high level of volatility around each compliance event. Industrial installations have the obligation to surrender to the EC the exact number of allowances that matches their verified emissions each year around end of March. The official report by the European Commission is disclosed by mid-May, but installation operators have already a fair amount of information between the publication of their own report and the compilation of verified emissions by the European Commission to approximate the total level of emissions relative to allowances allocated and to adjust their anticipations ${ }^{6}$.

Third, installations do not need to physically hold allowances during the year to produce, but only to match the required number of allowances with verified emissions for their yearly compliance report to the European Commission. Consequently, the probability of a potential illiquidity trap exists if market participants face a market squeeze during the compliance event. Another specificity of emission allowances may be highlighted: compared to stocks which are valid during the entire lifetime of the firm, emission allowances are vintaged for a given compliance year and cannot be used for future compliance periods, unless intertemporal flexibility mechanisms are authorized. During Phase I of the EU ETS, the inter-period transfer of allowances has been restricted by all Member States (Alberola and Chevallier, 2009).

\section{COMMON RISK FACTORS}

Similarly, we may identify several common risk factors between EUAs and CERs.

\footnotetext{
${ }^{6}$ The data in Figure 1 reveals a sharp break in EUA price series during the 2005 compliance event. By the end of April 2006, this price correction of 54\% within four days followed the announcement by the $\mathrm{EC}$ that $\mathrm{CO}_{2}$ emissions were approximately $3 \%$ lower than the allocated allowances during the 2005 compliance period (Alberola et al., 2008).
} 
1. The ITL-CITL connection

On 19 October 2008 the European Commission's "Community Independent Transaction Log" (CITL) connected to the United Nations' "International Transaction Log" (ITL). The ITL-CITL connection involved the EU's 27 Member States disconnecting their national registries, and re-connecting them to the ITL. Simultaneously, the CITL connected directly to the ITL. These operations allowed the delivery of sellers' international credits from the Kyoto Protocol (such as CERs) into buyers' EU national registries. Before that date, issued CERs remained in the UN CDM Registry, waiting for the connection with the EU registry to be completed.

During Phase II of the EU ETS (2008-2012), the EU Commission has announced that the use of CERs by industrial installations will be capped at 270 million tons per year. For Phase III (2013-2020), the limit for existing installations will be 40 million tons per year. Altogether, Phase III CER imports will add up to 300 million tons. Thus, the post-2008 EU ETS CER import limit has been fixed at 1.7 billion tons. ${ }^{7}$ Therefore, the ITL-CITL connection has filled the risk factor common to CDM project developers and investors. First, it has provided stimulus to CER and EUA trading, as the barriers to transfer allowances between UN and EU registries have been removed. Second, it has offered to EU investors in CDM projects the possibility to monetize their assets, by using CERs towards their own compliance or by exchanging them on the European market as secondary CERs. However, it seems worth noting that some types of CERs credits are restricted from use in the EU ETS, such as Land Use, Land Use Change and Forestry (LULUCF) projects.

\footnotetext{
${ }^{7}$ See http://ec.europa.eu/environment/climat/emission/ets post2012 en.htm
} 
2. The import limit of CERs within the EU emissions trading system

Since the ITL-CITL connection, Kyoto credits may be imported into the EU ETS, and are valid for compliance up to $13.4 \%$ on average. As detailed in Section 2.1, the EUA-CER price arbitrage becomes possible up to that limit. Investors will maximize their profits by buying the maximum volume of CERs allowed for compliance and selling the same amount EUAs when the EUA-CER spread is at its maximum, i.e. in the range of $€ 6$ to $€ 9$. Alberola et al. (2010) provide a detailed analysis of the determinants of EUA and CER prices. Besides, they study the determinants of the EUA-CER spread with regard to market microstructure mechanisms (such as the volume of allowances exchanged, etc).

Concerning the role played by the CER import limit for compliance within the EU trading system, we may proceed with the following counter-factual exercise. Eighty million tons of CERs have been used for compliance to cover verified emissions in 2008 (according to the EU Commission). ${ }^{8}$ At the same time, 250 million tons of CERs have been issued (according to the CDM Pipeline). If we assume the CER issuance rate to be constant, ${ }^{9}$ we obtain the path for the stock of CERs available for compliance within the EU ETS over time as depicted in Figure 2.

\footnotetext{
${ }^{8}$ See http://ec.europa.eu/environment/climat/emission/citl_en.htm

${ }^{9}$ Note this assumption is not overly restrictive. As detailed in Section 2.3, this rate is even likely to be decreasing.
} 
Figure 2: CER Stock available for EU ETS Compliance

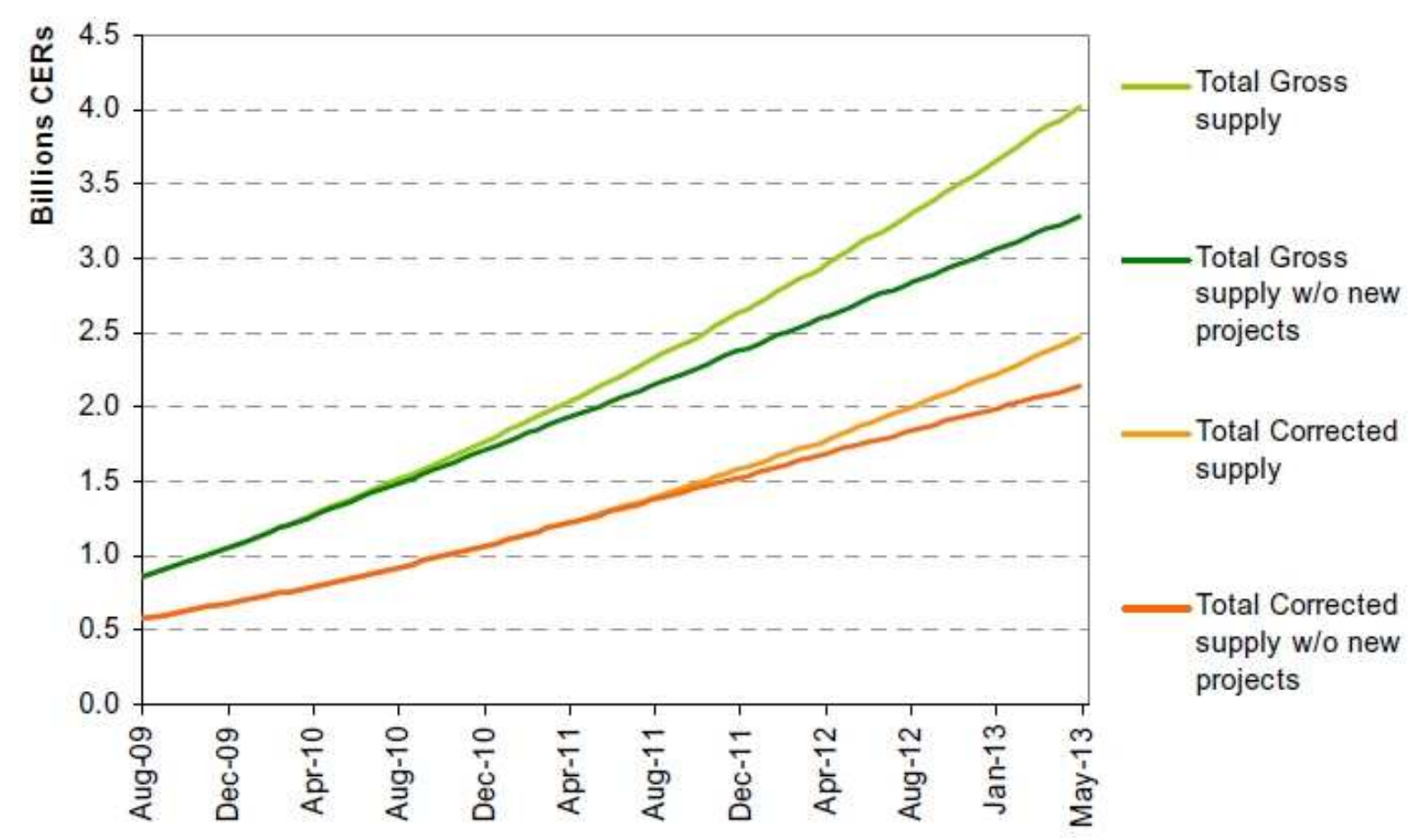

Source : Mission Climat of Caisse des Dépôts, from UNEP Risoe CDM Pipeline

Figure 2 shows the path of CERs available for compliance in the EU ETS at time $t$ during Phase II (2008-2012). The solid orange lines denote the stock of CERs available corrected for various issuance uncertainties, while the solid green lines indicate the total gross supply of CER issued. We observe on this graph that, due to technical and institutional constraints, firms could not use more than 1.6 Gt of CERs by April 2013 (Trotignon and Leguet (2009)). Besides, the yearly CER import limit does not seem to be binding before the 2010 compliance event. ${ }^{10}$ The path of CER delivery displayed in Figure 2 critically depends on the criteria for CDM project validation.

In terms of expected CER delivery, $\mathrm{HFC}, \mathrm{PFC}, \mathrm{CH}_{4}$, and $\mathrm{N}_{2} \mathrm{O}$ emission-reduction projects have a relatively large market share, which is mainly due to these gases' high global warming potential. It is also important to look at the distribution of projects and technologies

\footnotetext{
${ }^{10}$ As is characteristic of the functioning of the EU ETS, there is a one-year delay in the accounting of verified emissions. Thus, the 2010 compliance event will occur in May 2011.
} 
in terms of expected GHG emission reductions. Twenty-two projects involving HFC emissions reductions constitute $17 \%$ of expected emissions reductions by $2012 .{ }^{11}$ Sixty-five projects involving $\mathrm{N}_{2} \mathrm{O}$ emissions reductions constitute $9 \%$ of expected CERs ${ }^{12}$ (World Bank, 2008). By contrast, the 1,098 hydro projects will deliver just $17 \%$ of expected CERs. The distribution of issued CERs issued by technology is important to keep in mind, since HFCprojects (and other gases for which CERs are heavily issued) may not allowed for import in the EU ETS towards Phase III.

In terms of risk-assessment, it is also interesting to note that the delivery of credits, and thus the performance of projects, greatly varies: only 10 to $15 \%$ of methane reduction credits could be verified and therefore issued (World Bank, 2008). This ratio is $75 \%$ for HFC 23 emissions reduction projects, while $\mathrm{N}_{2} \mathrm{O}$ projects sometimes deliver more CERs than expected.

3. Uncertainties concerning Post-Kyoto agreements

Of course, the list of common risk factors between the CDM and EU ETS markets would not be complete without a careful outlook of negotiations for a post-Kyoto treaty. The European Commission has underlined its will to wait for the outcome of the December 2009 Copenhagen Summit before taking final decisions concerning CERs use in Phase III of the EU ETS (2013-2020). For instance, on technological grounds, CERs generated through HFC destruction or large hydro projects may be banned from import within the EU ETS.

\footnotetext{
${ }^{11}$ Indeed, the HFC global warming potential is 11,700 times higher than $\mathrm{CO}_{2}$, and thus each ton of HFC abated delivers 11,700 CERs.

${ }^{12}$ The $\mathrm{N}_{2} \mathrm{O}$ global warming potential is 310 times higher than $\mathrm{CO}_{2}$.
} 


\section{CONCLUSION}

This article critically examines the role played by Clean Development Mechanism projects for compliance into the EU Emissions Trading Scheme. We have highlighted risk factors specific to each emissions market - additionality and predictability for CERs, grandfathering, compliance events and banking provisions for EUAs - as well as common risk factors - the ITL-CITL connection, the role played by the $1.7 \mathrm{Gton}$ import limit, and uncertainties concerning future international agreements on climate change.

My conclusion cautions towards a prudent approach concerning the use of CERs for compliance within the EU trading system. On the one hand, CERs foster investments in nonpolluting technologies in non-Annex B countries. These project thereby contribute to the "global public good" of fighting climate change by cutting greenhouse gas emissions with a maximum potential (as for HFC destruction or large hydro projects) at lowest cost, and should be encouraged from both economic and environmental viewpoints. On the other hand, the unlimited use of CERs for compliance within the EU ETS would set a price floor for EUAs, and drive down their price. This solution does not appear compatible with the necessary "price signal" of emitting one ton of $\mathrm{CO}_{2}$ in the atmosphere in Europe, which should be high enough to provide incentives for industries to cut back emissions compared to their business-as-usual scenario.

The bottom line is that the restricted use of CERs for compliance within the EU ETS appears a wise choice from the EU Commission's viewpoint, in order 1) to limit design inefficiencies that have already affected the price path of EUAs during Phase I (2005-2007) and 2) to foster investments at the EU level in less $\mathrm{CO}_{2}$-intensive production processes. 


\section{References}

Alberola, E., Chevallier, J. (2009). European Carbon Prices and Banking Restrictions: Evidence from Phase I (2005-2007). The Energy Journal 30(3), 51-80.

Alberola, E., Chevallier, J., Chèze, B. (2008). Price drivers and structural breaks in European Carbon Prices 2005-07. Energy Policy 36 (2), 787-797.

Alberola, E., Chevallier, J., Hervé-Mignucci, M., Mansanet-Battaler, M. 2010. The EUA-sCER Spread: Price Arbitrage and Compliance Strategies in the European Carbon Market. Mission Climat Working Paper \#2010-06.

IPCC, (2007), Climate Change 2007, Fourth Assessment Report, United Nations Intergovernmental Panel on Climate Change, Bonn.

Trotignon, R. and Leguet, B. 2009. How Many CERs by 2013? Mission Climat Working Paper \#2009-05.

World Bank, (2008), State and Trends of the Carbon Market 2008, World Bank Institute, Washington DC, USA. 